\title{
Students with Learning Disabilities' Satisfaction, Employment, and Postsecondary Education Outcomes
}

\author{
Karen Rabren ${ }^{1}$, Ronald C. Eaves ${ }^{1}$, Caroline Dunn ${ }^{1} \&$ Craig Darch ${ }^{1}$ \\ ${ }^{1}$ Department of Special Education, Rehabilitation, \& Counseling, Auburn University, Alabama, USA \\ Correspondence: Karen Rabren, College of Education, Department of Special Education, Rehabiltiation \& \\ Counseling, 2084 Haley Center, Auburn University, Alabama 36849, USA. Tel: 1-334-844-2082. E-mail: \\ rabreks@auburn.edu
}
Received: February 4, 2013
Accepted: February 25, 2013
Online Published: April 2, 2013
doi:10.5539/jel.v2n2p14
URL: http://dx.doi.org/10.5539/jel.v2n2p14

\begin{abstract}
This study investigates the construct of satisfaction as a post-school outcome for students with learning disabilities (LD). More specifically, the effects of postsecondary education or training as well as employment are examined as they contribute to the overall satisfaction of young people with LD, one year after they exit high school. The rationale for this approach is that examining individuals' with LD satisfaction with their post-school outcomes will take into consideration their perspectives and provide an indication of whether or not they are engaged in post-school activities of their preference and also provides a broader approach to measuring post-school outcomes. Results of this study suggest that both education or training and employment are importantly influential in postsecondary satisfaction among individuals with learning disabilities as they transition from school to post-secondary activities.
\end{abstract}

Keywords: learning disabilities, post-school outcomes, satisfaction, employment, postsecondary education

\section{Introduction}

\subsection{Students with Disabilities' Postschool Outcomes}

The 1980s produced the first generation of students with disabilities who were exiting high schools after gaining access to a public education afforded to them through the Education for All Handicapped Children Act of 1975. Although these students now had the right to a public education, it was soon recognized that access alone did not always result in positive post-school outcomes. This discouraging realization was made evident by the insurmountable challenges these young people were experiencing after leaving high school. Although, in recent years the post-school outcomes of students with disabilities have improved, they continue to have poorer occupational outcomes and attend postsecondary education institutions at a lower rate than their peers without disabilities (Newman, Wagner, Cameto, \& Knokey, 2009).

In spite of the post-school challenges faced by youth with disabilities, those with learning disabilities (LD) in particular, still have high aspirations for their post-school success. For instance, one statewide study found that 80 percent of students with LD had set goals for employment and almost 70 percent were hopeful for some type of postsecondary education (Daviso, Denney, Baer, \& Flexer, 2011). As students with LD exit high school and enter the world of work and/or postsecondary education, a question to be considered is how satisfied they are with their post-school outcomes.

\subsection{Examining Post-School Outcomes}

The purpose of this study is to examine the effects of postsecondary education or training as well as employment as each contributes to the overall satisfaction of young people with learning disabilities after they leave high school. The rationale for this approach is that by examining individuals' with LDs satisfaction with their post-school outcomes consideration of their perspectives can provide an indication of whether or not they are engaged in the post-school activities of their preference. Consequently, this will provide a more encompassing approach to measuring post-school outcomes since satisfaction can be considered one's own assessment of his or her current status in life. Given that students' preferences and interests must be considered during their transition planning, as required by the Individuals with Disabilities Education Improvement Act (2004), it seems logical to consider students' satisfaction with their post-school activities. Ideally, if appropriate transition planning has 
taken place, students with LD, as well as other disabilities, will be engaged in their post-school activities of their choice and be satisfied with their post-school outcome achievements.

\subsection{Employment, Postsecondary Education \& Satisfaction}

Highlights of previous research of postsecondary employment and education for persons with LD are presented to provide an overview of the post-school outcomes these young people have been able to achieve in recent years. Next, the concept of satisfaction is introduced as a measure of post-school outcomes, paying special attention to this variable and its implications for students with LD.

\subsubsection{Employment}

The results of outcome studies reveal that many young adults with LD experience problems related to employment (underemployment, low wages, and frequent job changes), participation and success in post-secondary settings, involvement in community and leisure activities, and dependency on parents and others (Benz, Lindstrom, \& Yovanoff, 2000; Blackorby \& Wagner, 1996; Scanlon \& Mellard, 2002). For example, in the area of employment, a number of studies have documented the low employment rates for students with disabilities. Using data from the National Longitudinal Transition Study-2 (NLTS-2); Newman, Wagner, Cameto, and Knokey (2009) indicated that approximately 64 percent of youth with LD who had left high school were employed for pay outside the home. For youth without disabilities, the rate of employment was 66 percent. While the employment rate for individuals with LD is close to that of the general youth population, the NLTS-2 data revealed that youth with LD tend to keep their jobs for a shorter period of time. For youth who had been out of school 1-4 years, those with LD had a job duration average of 9.9 months, whereas, youth in the general population had a job duration average of 14.7 months. Further, youth with LD had an average of 2.9 jobs since leaving high school.

\subsubsection{Post-Secondary Education}

With regard to participation in postsecondary programs (i.e., vocational, business, technical school; 2-year or community college, 4-year college), NLTS-2 data indicated that only 47 percent of youth with LD who had been out of school up to 4 years had continued their education beyond high school in these programs. The majority of students with disabilities were attending vocational, business or technical schools, or 2-year colleges. For 4-year colleges, only 7.6 percent of youth with disabilities as compared to 29.2 percent of those in the general population were attending these institutions of higher education.

Although the type of postsecondary education of choice may vary, it is important to note that there has been a significant increase in students with LD who attend any type of postsecondary education program (Newman, Wagner, Cameto, Knokey, \& Shaver, 2010). More specifically, the postsecondary enrollment rates of youth and young adults with LD from 1990 to 2005 indicate a 19 percent increase in attendance in 2-year or community colleges and an 11 percent increase in the enrollment rate in 4-year colleges. Although the increase in postsecondary enrollment for persons with LD is encouraging, problems associated with having a learning disability do not disappear upon graduation from high school. Individuals with LD must continue to contend with the effects of their LD in an even more demanding educational environment without many of the supports previously available during high school.

Students with disabilities need access to educational accommodations, supports, and services in order to be successful in their postsecondary education environments (Tagayuna, Stodden, Zeleznik, \& Whelley, 2005). In order to benefit from these supports and services, students must first fully understand their disability and describe to others the supports they need. Unfortunately, many do not take advantage of what is available to them, because it has been found that 68 percent of students with LD enrolled in postsecondary schools do not consider themselves to have a disability nor have they informed their postsecondary institution of their disability (Newman et al., 2011).

\subsubsection{Satisfaction}

Although less than optimal post-school outcomes for persons with disabilities in the areas of employment and post-secondary education are a reason to be concerned, another variable to be considered is the degree to which these individuals are satisfied with their lives. Satisfaction is considered as a part of the personal fulfillment domain used to describe quality of life outcomes. As one of his six recommendations for future research Halpern (1993) implored the field, "We must begin to attend more routinely to the subjective dimensions of quality of life as important criteria for evaluating the impact of transition programs" (p. 497). According to his definition, quality life consists of three specific content domains "(1) physical and material well-being, (2) performance of a variety of adult roles, and (3) a sense of personal fulfillment” (p. 490). Halpern further broke down the personal 
fulfillment domain into the content areas of satisfaction and general well-being, which he considered to be requirements for a satisfactory quality of life. Therefore, examining the satisfaction of former students who have disabilities is a move toward providing a more holistic view of the post-school outcome status of these young people.

Persons with disabilities have been found to be significantly less satisfied with their life than those without disabilities (Barton, 2009; Marinic \& Brkljacic, 2008). Life satisfaction affects people's happiness and their ability to perform in other areas of their lives such as employment. Defining life satisfaction can be difficult. In this study we will use the same definition as used in a previous study by Corrigan, Bogner, Mysiw, Clinchot, and Fugate (2001) who examined the life satisfaction of persons with traumatic brain injury. These researchers define life satisfaction as, "a cognitively oriented, subjective judgment of one's current life situation in relation to one's own expectations" (2001, page 544). We choose this definition because it best represents the manner in which life satisfaction was determined in this study - that is former students with LD were asked to make a judgment of their own satisfaction with their lives 1 year after their exit from high school. We will use this definition to determine if there are any influences on these students' life satisfaction.

\subsection{Influences on Post-School Satisfaction}

Previous studies have examined the employment satisfaction of persons with learning disabilities (Madaus, Zhao, \& Ruban, 2008); however, this study will examine the construct of satisfaction with this population from another perspective. Instead of focusing on the satisfaction that those with learning disabilities derive from employment, we will be looking at the effects of postsecondary education or training as well as employment as each contributes to the overall satisfaction of young people 1 year after they exit high school. In so doing, our goal is to examine more comprehensively the influences on satisfaction of young people with disabilities, specifically those with learning disabilities.

We have designed this study to address the following research questions.

\subsubsection{Research Questions}

1) What is the influence of postsecondary education/training on postsecondary satisfaction?

2) What is the influence of postsecondary employment on postsecondary satisfaction?

3) Is there an interaction between postsecondary education/training and postsecondary employment on postsecondary satisfaction?

\section{Method}

\subsection{The Alabama Post-School Transition Survey}

The Alabama Post-School Transition Survey was administered to former students with disabilities who received special education services while in high school and who had been out of school for 1 year during 2007 and 2008 . Of the 1,341 former students participating in the survey during 2007 and 2008, 801 (59.7\%), were identified as having learning disabilities, 297 (22.1\%) with mental retardation [sic] (intellectual disabilities), 27 (2.0\%) with emotional disturbance, and the remaining 245 (18.3\%), with low incidence disabilities. Of these, former students with LD were the focus of this study. The 801 participants of this study were representative of the State's average on the demographic dimensions of gender, ethnicity, and disability (LD) as available from annual Child Count data. Specifically, participants' gender was $\pm 2.4 \%$ and race was $\pm 0.9 \%$ of the State population of students at the time of the study. In addition, we present summary statistics for participants' educational setting and exit status in Table 1. 
Table 1. Distribution of race, gender, educational setting in the sample

\begin{tabular}{lcc}
\hline Group & Frequency & Percent \\
\hline Race & 364 & 45.4 \\
$\quad$ African American & 411 & 51.3 \\
$\quad$ White & 26 & 3.2 \\
$\quad$ Missing Information & & \\
Gender & 254 & 31.7 \\
$\quad$ Female & 547 & 68.3 \\
$\quad$ Male & & \\
Educational setting & 503 & 62.8 \\
80-100\% of Time in General Education & 188 & 23.5 \\
40-79\% of Time in General Education & 93 & 11.6 \\
$\quad<40$ of Time in General Education & 17 & 2.1 \\
Missing Information & & \\
Exit Status & 159 & 19.9 \\
Graduation Certificate & 241 & 30.1 \\
Occupational Diploma & 357 & 44.6 \\
High School Diploma & 44 & 5.5 \\
Missing Information & 801 & 100.0 \\
Total & & \\
\hline
\end{tabular}

\subsection{Sampling Procedures}

Data for this study were derived from the 2007 and 2008 administration of the Alabama Post-School Transition Survey. Administration procedures for this statewide survey required Local Education Agency (LEA) personnel to conduct phone interviews with former students with disabilities and enter responses on-line into the State's secure Student Information System. A "sample over time without replacement" was used to identify districts that participated in the annual administration of the State's post-school outcome survey (Bullis, p. 10). This sample was based on set of criteria derived from the State's Child Count demographic information on (a) the number of students with and without disabilities, (b) the number of 15-year-olds, (c) a count of students receiving free and reduced lunch, and (d) the geographic region of the school systems. Statewide averages were then calculated using these criteria and a representative sample of 40 school districts was selected with plus or minus $3 \%$ error rates (Bullis, 2005).

\subsubsection{Procedures}

The post-school survey used in this study was derived from an adaptation of Vermont's Post-School Indicators Follow-Up Questionnaire (Hasazi, Hock, \& Cravedi-Cheng, 1992). In the mid-1990s, Alabama adopted a modified version of this survey for post-school outcome data collection with their students with disabilities. A multidiscipline feasibility task force assisted in the revision of the Vermont survey and adoption of Alabama's post-school survey. After a number of meetings and field-testing, an agreement on the number and type of items was obtained.

A comparison of content domains of the Alabama Post-School Transition Survey with those found in the National Longitudinal Transition Survey (NLTS2) revealed that Alabama's survey includes content from six of the eight domains found in the NLTS2. The post-school survey includes dichotomous yes and no responses, as well as three-point Likert Scale responses of much, some, and none. There are also two multiple-choice items that require a click only one response, and one item that requires students to choose between two possible responses. The survey ends with an open-ended response item.

For the years 2007 and 2008, the Alabama Post-School Transition Survey contained 30 items that were relevant to post-school outcomes. Principal axis factor analysis of the survey resulted in three factors: postsecondary 
education/training, employment, and satisfaction. Table 2 shows the items that loaded on each of these factors. Thirteen items did not load on any factor. It will be noticed that none of the items loading on the satisfaction factor involve postsecondary education/training or employment. Rather, they concern other aspects of satisfaction, as well as quality of life (e.g., family life, friendships, community life, use of free time).

Table 2. Alabama Post-School Outcomes Survey (2007-08) items and pattern coefficients

\section{Education and Training}

Are you enrolled in any type of school, training, or education program?

Are you satisfied with your postsecondary education?

At any time since you left high school, have you had education or training in a two-year .48 community college?

How satisfied are you with your education or training?

At any time since you left high school, have you had education or training in a four-year .34 community college?

\section{Employment}

Are you working now?

At any time since leaving high school, have you had a job?

Does the job provide health insurance?

Describe the job setting for the longest held job.

Does the job provide sick leave?

How satisfied are you with your work?

\section{Satisfaction}

How satisfied are you with your family life?

How satisfied are you with your community life?

How satisfied are you with your friends?

How satisfied are you with your free time?

A simple sum of each participant's responses was used to derive scores for the three factors. Using a median split of the scores, the participants were blocked into two groups (high and low scores) for the two independent variables (postsecondary education/training and postsecondary employment).

\subsubsection{Analysis}

The Statistical Package for the Social Sciences (SPSS Version 18.0, 2009) was used to analyze the data for this investigation. A two-factor univariate analysis of variance tested the influence of post-secondary education/training and employment on satisfaction. Scheffé post hoc tests were used to evaluate statistically significant interaction effects.

\section{Results}

Cronbach's coefficient alpha was used to estimate the reliability of the independent and dependent variables. The postsecondary education and training score had an alpha of .72 in this sample; alpha for the postsecondary employment score was .82 . For the postsecondary satisfaction score the coefficient alpha was .86. All of these values are well above the criterion of .60 , which is often cited as the minimal reliability of scores used in research (Salvia \& Ysseldyke, 2007).

Table 3 presents the means, standard deviations, and results of the analysis of variance of the influence of post-secondary education/training and employment on satisfaction. The $F$-values of both main effects and the interaction effect were statistically significant. 
Table 3. Means, standard deviations, analysis of variance, and simple effects

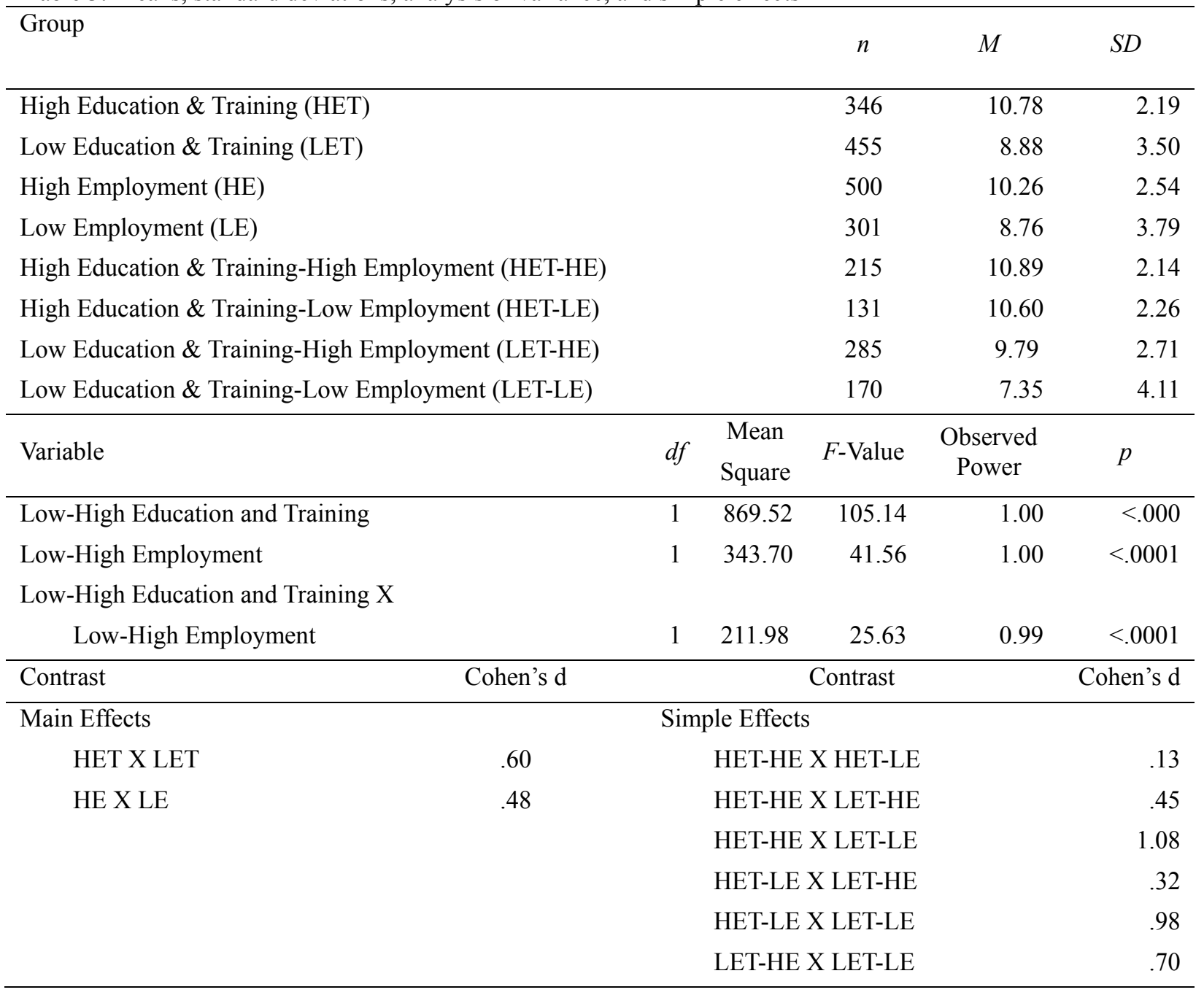

The attainment of post-secondary education and training served as an important influence on satisfaction $(F=$ $105.14, p<.0001)$. Cohen's $d$ yielded a moderately large effect size of .60 . High education/training scores led to greater satisfaction.

Participants with high employment scores had high satisfaction scores relative to those participants who produced low employment scores $(F=41.56, p<.0001)$. Cohen's $d$ was .48 , which is a small, but nontrivial effect size. 


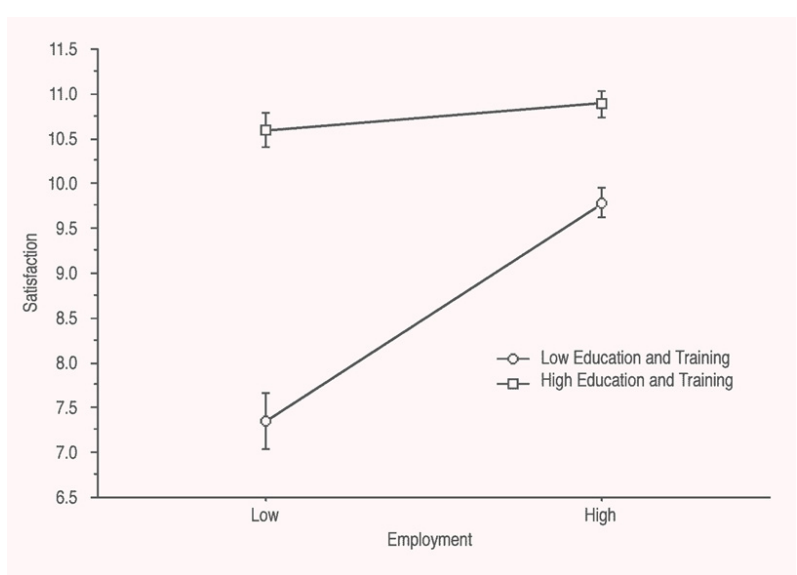

Figure 1. Interaction between education and training and employment on postsecondary satisfaction

The Scheffé post hoc tests revealed the simple effects of the significant interaction. Figure 1 graphically displays the results. All contrasts were significantly different save one-the high education and training-high employment group was not different from the high education and training-low employment group $(p=.36, d=.13)$. The remaining contrasts were statistically different. That is, the high education and training-high employment group had higher satisfaction scores than the low education and training-high employment group $(p<.0001, d=.45)$. The high education and training-high employment group had higher satisfaction scores than the low education and training-low employment group $(p<.0001, d=1.08)$. The high education and training-low emploment group had higher satisfaction scores than the low education and training-high employment group $(p<.008, d$ $=.32$ ). The high education and training-low employment group had higher satisfaction scores than the low education and training-low employment group $(p<.0001, d=.98)$. Finally, the low education and training-high employment group had higher satisfaction scores than the low education and training-low employment group $(p$ $<.0001, d=.70)$.

\section{Discussion}

The results of our study advance the field of transition research in several important ways. First, we have used factors consisting of a number of items instead of single items to measure post-school outcomes. Much of the existing transition research uses individual items as independent and dependent measures. In this study, three measures or variables of post-school outcomes, which were derived from a factor analysis of 30 items relevant to post-school outcomes, were examined. Additionally, we have taken a broader approach to measuring post-school outcomes by including individuals' with LD satisfaction with their post-school outcomes. This approach provides preliminary information about students' self-assessment of their post-school outcome status and whether or not they are content with their current situation.

The reliability estimates of the three variables analyzed in this investigation were .72 (postsecondary education/training), .82 (employment), and .86 (postsecondary satisfaction). These relatively strong estimates of item homogeneity resulted from the fact that the scales were derived through factor analysis. We believe that this approach represents an improvement over the common use of individual items as independent and dependent measures in transition research.

The results indicated that, even though our measure of satisfaction specifically excluded elements of postsecondary education/training and postsecondary employment, nevertheless, the influence of the latter constructs on postsecondary satisfaction was statistically significant. One significant main effect showed that participants with high education/training scores had higher satisfaction scores than those with low education/training scores. Likewise, participants with high employment scores had higher satisfaction scores than those with low employment scores. The significant interaction effect showed that five of six simple effect contrasts were significantly different. There was an orderly decline in means from the high education/training-high employment group $(M=10.89)$ down to the low education/training-low employment group $(M=7.35)$. Based on large effect sizes the group of greatest concern is the low education/training and low employment group who were significantly lower than all of the three groups. This indicates that participants in this group were the least satisfied with their post-school outcomes.

Given the very high power that obtained in this study (i.e., .99-1.00), it is important to evaluate the magnitude of 
the effect sizes of the results. The six statistically significant effect size statistics (i.e., Cohen's $d$ ) ranged from .32 to 1.08 (median $d=.60$ ). Three of the $d$ s may be characterized as weak, but not trivial (i.e., .30-.49), two $d$ s were of a moderate size (i.e., .50-.79), and two $d$ s were strong (i.e., $\geq .80$ ). This suggests that the statistically significant $F$ values did not result simply from the large sample size; they appear to have considerable practical significance as well.

As previously defined, satisfaction was measured by participants' own appraisal of their life. If we take into consideration that satisfaction is considered a component of one's quality of life, these findings provide an even stronger argument that there is a need to continue working toward improving the post-school outcomes for former students with disabilities and to examine these students' post-school outcomes in a broader context. More specifically, as found in this study, those former students with a lower status in both employment and education or training also were less satisfied with their current situation in these areas. This suggests that they recognize the need for improvement and this lack of satisfaction is impacting their quality of life.

\subsection{Limitations}

One limitation of this study is that it was conducted in a single southeastern state; therefore, caution should be taken in generalizing its findings to other areas of the United States. Another limitation of this study, which has been identified in other post-school outcome studies (e.g., Daviso et al., 2011) is that teachers served as the interviewers in this study. However, this limitation is addressed by the use of an administrator's manual to be used by the teachers and periodic post-school outcome survey training.

\subsection{Summary and Recommendations}

This study examined the effects of postsecondary education or training and employment as they contribute to the overall satisfaction of young people with LD, lyear after they exit high school. The inclusion of satisfaction as a variable to be considered provides a more holistic approach to studying the post-school outcomes of youth with $\mathrm{LD}$, which addresses their own determination of their quality of life.

It was 20 years ago that Halpern (1993) made a plea that we estimate the success of transition programs with a broader perspective than simply employment. Yet, very little transition research has made quality of life the focal outcome variable. Although this investigation fell short of Halpern's ambitious objective, our dependent measure did incorporate six aspects of satisfaction, excluding employment and education/training. Our findings suggest that both education/training and employment are importantly influential in postsecondary satisfaction among individuals with learning disabilities as they transition from school to post-secondary activities. We recommend that future studies include the development of even more reliable and valid measures of both in-school variables and post-school outcomes in order to move the discipline forward.

\section{References}

Barton, B. (2009). Dreams deferred: Disability definitions, data, models, and perspectives. Journal of Sociology \& Social Welfare, 34, 13-24.

Benz, M., Lindstrom, L., \& Yovanoff, P. (2000). Improving graduation and employment outcomes of students with disabilities: Predictive factors and student perspectives. Exceptional Children, 66(4), 509-529.

Blackorby, J., \& Wagner, M. (1996). Longitudinal postschool outcomes of youth with disabilities: Findings from the National Longitudinal Transition Study. Exceptional Children, 62, 399-413.

Bullis, M. (2005). Post-school outcomes for youth with disabilities: Establishing a representative sample of your state to address indicator \#14. National Post-school Outcomes Center. Retrieved September 10, 2007 from http://www.psocenter.org/collecting.html\#post

Corrigan, J. D., Bogner, J. A., Mysiw, W. J., Clinchot, D., \& Fugate, L. (2001). Life satisfaction after traumatic brain injury. Journal of Head Trauma Rehabilitation, 16, 543-555. http://dx.doi.org/10.1097/00001199-200112000-00003

Daviso, A. W., Denney, S. C., Baer, R. M., \& Flexer, R. (2011). Postschool goals and transition services for students with learning disabilities. American Secondary Education, 39, 77-93.

Falls, J. (2006, March). Northwest forum on post-school outcomes, Portland, Oregon, (Available from the National Post-school Outcome Center, 1268 University of Oregon, Eugene, OR 97403-1268).

Halpern, A. S. (1993). Quality of life as a conceptual framework for evaluating transition outcomes. Exceptional Children, 69, 486-498.

Hasazi, S., Hock, M., \& Cravedi-Cheng, L. (1992). Vermont's post school indicators: Using satisfaction and post 
school outcomes data for program improvement. In F. Rush, L. DeStefano, J. Chadsey-Rush, J. A. Phelps, \& E. M. Szymanski (Eds.), Transition from school to adult life: Models, linkages, and policy (pp. 485-508). Champaign, IL: Sycamore.

Madaus, J. W., Zahao, J., \& Ruban, L. (2009). Employment satisfaction of university graduates with learning disabilities. Remedial and Special Education, 29, 323-332. http://dx.doi.org/10.1177/0741932507312012

Marinic, M., \& Brkljacic, T. (2008). Love over gold - The correlation of happiness level with some life satisfaction factors between persons with and without physical disability. Journal of Developmental and Physical Disabilities, 20, 527-540. http://dx.doi.org/10.1007/s10882-008-9115-7

Newman, L., Wagner, M., Cameto, R., \& Knokey, A. M. (2009). The post-high school outcomes of youth with disabilities up to 4 years after high school. A report of findings from the National Longitudinal Transition Study-2 (NLTS2). (NCSER Report No. 2009-3017).

Newman, L., Wagner, M., Cameto, R., Knokey, A. M., \& Shaver, D. (2010). Comparisons across time of the outcomes of youth with disabilities up to 4 years after high school. A report of findings from the National Longitudinal Transition Study-2 (NLTS2). Menlo Park, CA: SRI International. (NCSER Report No. 2010-3008).

Newman, L., Wagner, M., Knokey, A.-M., Marder, C., Nagle, K., Shaver, D., Wei, X., Cameto, R., Contreras, E., Ferguson, K., Greene, S., \& Schwarting, M. (2011). The Post-High School Outcomes of Young Adults With Disabilities up to 8 Years After High School. A Report from the National Longitudinal Transition Study-2 (NLTS2) (NCSER 2011-3005). Menlo Park, CA: SRI International. Retrieved from http://www.nlts2.org/reports/

Salvia, J., \& Ysseldyke, J. E. (2007). Assessment in special and inclusive education (10th ed.). Boston, MA: Houghton Mifflin.

Scanlon, D., \& Mellard, D. F. (2002). Academic participation profiles of school-age dropouts with and without disabilities. Exceptional Children, 68, 239-258.

SPSS Inc. (2009). PASW Statistics for MacIntosh, Version 18.0. Chicago: SPSS Inc.

Tagayuna, A., Stodden, R. A., Chang, C. Z., \& Whelley, T. A. (2005). A two-year comparison of support provision for persons with disabilities in postsecondary education. Journal of Vocational Rehabilitation, 22, $13-21$.

\section{Notes}

Note 1. Data used in this study were collected under a contractual agreement between the Alabama Department of Education and the Auburn Transition Leadership Institute, Auburn University, Alabama. However, analysis conducted for the purposes of this study were beyond the contractual requirements of this agreement. 